\title{
Generalized Traditional Risk Factors of Being Overweight and Obesity among Ever Married Non-Pregnant Women in Bangladesh: An Application of Decision Tree Analysis
}

\author{
Mohammad Zahidul Islam \\ Lecturer, Department of Population Science, Jatiya Kabi Kazi Nazrul Islam \\ University, Mymensingh, Bangladesh
}

This journal is licensed under a Creative Commons Attribution-NonCommercial 4.0 International License (CC-BY-NC). Articles can be read and shared for noncommercial purposes under the following conditions:

- BY: Attribution must be given to the original source (Attribution)

- NC: Works may not be used for commercial purposes (Noncommercial)

This license lets others remix, tweak, and build upon your work non-commercially, and although their new works must also acknowledge you and be non-commercial, they don't have to license their derivative works on the same terms. License Deed Link: http://creativecommons.org/licenses/by-nc/4.0/ Legal Code Link: http://creativecommons.org/licenses/by-nc/4.0/legalcode $A B C$ Research Alert uses the CC BY-NC to protect the author's work from misuse.

\section{Abstract}

Background: As the prevalence of obesity increases, the co-existing underweight and increasing overweight has also become a public health problem in many developing countries like as Bangladesh. Therefore, this study seeks to identify the major determinants factors of being overweight or obese.

Methods: This study used a cross-sectional analysis from the 2011 Bangladesh Demographic and Health Survey that include 2,740 maternal women. To assess the determinants factors of overweight and obese, a multivariate technique name as decision tree analysis was used in this study.

Results: Around $68 \%$ of the maternal women were underweight and $32 \%$ were either overweight or obese. Women higher socio-economic status, women age $\geq 25$ years, higher educational level and urban place of residence were found to be most dominant factors of being overweight and obese.

Conclusion: The findings suggest that, the major policy implications of this study are the importance of socio-economic status women, age $\geq 25$ years with higher educational level and urban women to minimize its adverse effect on overweight and obese.

Keywords

Overweight, socio-demographic factors, decision tree approach, Bangladesh.

\section{BACKGROUND}

Globally the prevalence of overweight and obesity are increasing rapidly while the underweight continues to be common in low- and lower-middle income countries. Currently around 39\% of the world adult populations are overweight; around $13 \%$ of them were obese. This variation of the prevalence of overweight and obesity were also reported by geographically. In America, populations were found to be more prevalent of overweight $(61.3 \%)$ and obese $(26.8 \%)$ while lower prevalence of overweight $(22.2 \%)$ and obesity $(5 \%)$ reported among Asian population. Similarly, higher prevalence of underweight $(52.7 \%)$ reported in this region. 
In the last two decades, nutritional transition characterized by the trend of underweight to overweight or obese is the subject of increasing talk in Asian countries [1]. The commonly held perspective that before nutritional transition, overweight and underweight tend to be concentrate in high and low socio economic groups respectively [2]. However, developing countries experiencing the rapid mass of urbanization and globalization of food production which contribute to the overweight burden posited to shifts low socio economic groups, even though the underweight burden remains [3]. The potential coexist of this trend is an overlap between over and under nutrition not only in household [4] but also the individual [3]. Therefore, it is imperative that the pattering of under nutrition and overweight to inform the health policies for the management of nutrition related burden of diseases [5]. There are many report describing the epidemiological feature of the traditional risk factors of being undernourished and overweight in different circumstances. Khan et al [6] conducted a comparative study on the basis of Bangladesh Demographic and Health Survey (BDHS, 2007 \& 2011) data and found age, education, marital status, children ever born, wealth index, husband occupation and education as a most important determinants of nutritional status in both survey years. Khan and Kramer [7] conducted another study on 3634 ever married non pregnant women and found similar risk factors of being overweight and obese mentioned khan et al [6]. Corsi et al [8] also found BMI influenced by neighborhood variation in his study on 57 low and lower middle countries. They also found between the country, around $13.4 \%$ and $18.9 \%$ variation observed for underweight and overweight respectively. Beside these, some others study identified sex difference [9, 10], physical activity [11, 12], television watching habit [13, 14], dietary pattern [15], health knowledge [16] and acculturation [17] as a risk factors of overweight or obesity.

Furthermore, previous studies demonstrate that in order to determine the risk factors of overweight, logistic regression method was used. However, logistic regression has limitation in managing complicated data because many factors are involved that could affect each other's $[18,19]$. Such disadvantage could easily be overcome by decision tree analysis [20,21], screen for the most important risk factors and identify the cut points for risk factors. Therefore, we performed the decision tree analysis to identify the most important risk factors of being overweight.

\section{METHODS}

\subsection{Data}

Data were obtained from cross-sectional Bangladesh Demographic and Health Survey (BDHS, 2011). Using the multistage cluster sampling, BDHS collect all information including socio-economic, demographic and anthropometric, birth and health information from 17, 842 ever married women aged 15-49. We excluded women having no children in the last five years, having normal weight and currently pregnant in the second and third trimester. The final analyzed sample survey was 2,704.

\subsection{Dependent variable}

Maternal BMI status was considered as the dependent variable. Maternal BMI classified into four categories; underweight, normal weight, overweight and obese. Due to our study suitability, we omitted the women having the normal weight and include only underweight and overweight women.

\subsection{Independent variable}

We used different individual, household and community level characteristics as independent variable. Review of the previous study, we identify these selected variables. The considered independent variables are age (15-19, 20-24,25-29,30-34, 35-39, $\geq 40$ years), respondents education (no education, primary, secondary and higher education), respondents husband education (no education, primary, secondary and higher education), respondents socio economic status (poorest, poorer, average, richer, richest), region (Barisal, Chittagong, Dhaka, Khulna, Rajshahi, Rangpur, Sylhet), place of residence (urban, rural), present working status (yes, no), household food security (never, sometimes, few often) and the number of antenatal visit (no visit, less than or equal four visit, above four visit). 


\subsection{Statistical analysis}

To identify the optimal splits, this study used the Chi-squared Automatic Interaction Detection (CHAID) method. Decision tree analysis was used to assess the most important predicting variable of being overweight and obese. CHAID algorithm with growing criteria of the likelihood ratio Chi-square statistics was used for building the tree and evaluating the splits. To identify the nodes with a relatively high probability, a gain chart was constructed showing the nodes sorted by the number of cases in the target category for each node. All statistical analysis was performed by using SPSS 20.0 (SPSS Inc. Chicago, II, USA).

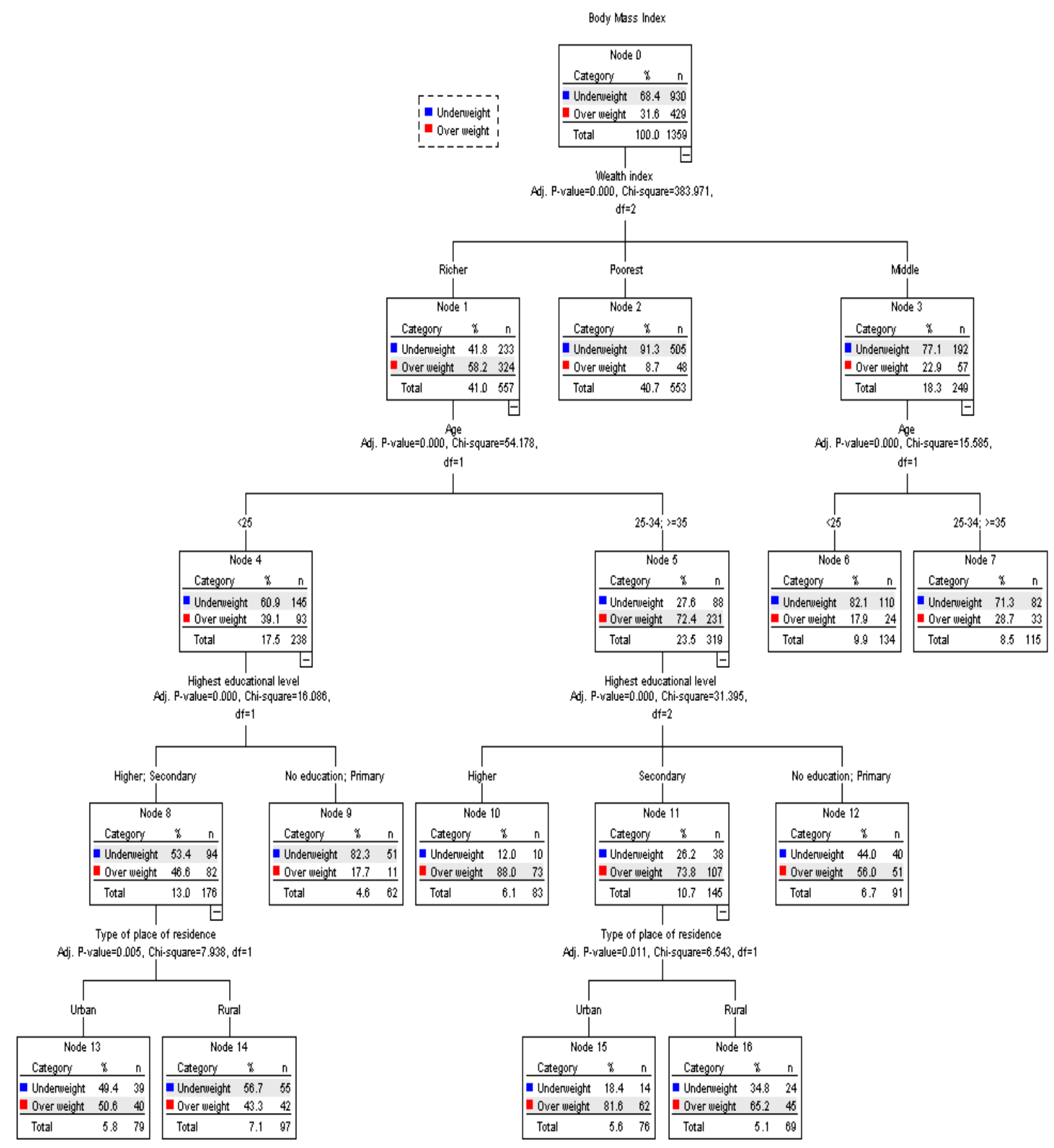

Chart: Body Mass Index 


\begin{tabular}{|c|c|c|c|}
\hline \multirow{2}{*}{$\begin{array}{l}\text { Traditional } \\
\text { Risk factors }\end{array}$} & \multicolumn{2}{|c|}{ Body Mass Index } & \multirow[t]{2}{*}{ P-value } \\
\hline & Underweight & Overweight/obese & \\
\hline \multicolumn{4}{|l|}{ Age (years) } \\
\hline$<25$ & $1024(79.1)$ & $270(20.9)$ & $<0.001$ \\
\hline $25-34$ & $668(57.2)$ & $500(42.8)$ & \\
\hline$\geq 35$ & $170(61.2)$ & $108(38.8)$ & \\
\hline \multicolumn{4}{|l|}{ Education } \\
\hline Illiterate & $450(85.7)$ & $75(14.3)$ & $<0.001$ \\
\hline Primary & 662 (79.6) & $170(20.4)$ & \\
\hline Secondary & $693(60.9)$ & $445(39.1)$ & \\
\hline Higher & $57(23.3)$ & $188(76.7)$ & \\
\hline \multicolumn{4}{|l|}{$\begin{array}{l}\text { Marital } \\
\text { status }\end{array}$} \\
\hline Married & $1823(67.7)$ & $870(32.3)$ & $<0.05$ \\
\hline Others & $39(83.0)$ & $8(17.0)$ & \\
\hline \multicolumn{4}{|l|}{$\begin{array}{l}\text { Present } \\
\text { working } \\
\text { status }\end{array}$} \\
\hline No & $1678(68.4)$ & 777 (31.6) & 0.110 \\
\hline Yes & $184(64.6)$ & $101(35.4)$ & \\
\hline \multicolumn{4}{|l|}{ Wealth Index } \\
\hline Poorer & 1028 (91.5) & $96(8.5)$ & $<0.001$ \\
\hline Middle & $368(77.1)$ & 109 (22.9) & \\
\hline Richer & $466(40.9)$ & $673(59.1)$ & \\
\hline \multicolumn{4}{|l|}{ Area of living } \\
\hline Rural & $1424(77.4)$ & $416(22.6)$ & $<0.001$ \\
\hline Urban & $438(48.7)$ & 462 (51.3) & \\
\hline \multicolumn{4}{|l|}{ Region } \\
\hline Barisal & $220(70.5)$ & $92(29.5)$ & $<0.001$ \\
\hline Chittagong & $323(64.6)$ & $177(35.4)$ & \\
\hline Dhaka & $291(65.4)$ & $154(34.6)$ & \\
\hline Khulna & 188 (59.3) & $129(40.7)$ & \\
\hline Rajshahi & $223(63.9)$ & $126(36.1)$ & \\
\hline Rangpur & $282(77.5)$ & $82(22.5)$ & \\
\hline Sylhet & $335(74.0)$ & $118(26.0)$ & \\
\hline \multicolumn{4}{|l|}{ CEB } \\
\hline$\leq 2$ & $1129(67.2)$ & $550(32.8)$ & $<0.001$ \\
\hline $3-4$ & $501(64.2)$ & $279(35.8)$ & \\
\hline$>4$ & $232(82.6)$ & $49(17.4)$ & \\
\hline \multicolumn{4}{|l|}{$\begin{array}{l}\text { Age at first } \\
\text { birth }\end{array}$} \\
\hline$\leq 18$ & $1292(75.6)$ & $416(24.4)$ & $<0.001$ \\
\hline $19-22$ & $467(60.9)$ & $300(39.1)$ & \\
\hline$>22$ & $103(38.9)$ & $162(61.1)$ & \\
\hline Total & $1862(68.0)$ & $878(32.0)$ & \\
\hline
\end{tabular}

Table 1: The comparison of traditional risk factors between BMI and anemia category

\section{RESULTS}

We analyzed the data of 2,740 women, between ages 15 to 49 . Most of the subject was underweight (68\%) and the resulting were overweight or obese $(32 \%)$. The respondents age were divided into three categories i.e., $<25,25-34$ and $\geq 35$. Within these groups, majority of the respondents were <25-year age groups. Majority of the illiterate (85.7\%) and primary (79.6\%) educated women were underweight while overweight found to be more prevalent among higher educated $(76.7 \%)$ women. Poorer women were more likely to underweight (91.55\%). Most of the rural women were underweight $(77.4 \%)$ and overweight $(51.3 \%)$ found to be more prevalent in urban area. Higher prevalence of underweight $(75.6 \%)$ found among the women whose were given birth before age $\leq 18$ years. 
We used the decision tree analysis to screen for the most important traditional risk factors of being overweight or obese. Of the nine variables that were entered in CHAID analysis, four variables were selected by the program for the classification tree. The four variables were: wealth index, age, highest educational level and type of place of residence.

The CHAID identified the variables that play the important role of being overweight (Fig. 1). This indicates that the wealth index was the most important determining factors. This first level split produces three initial branches of the classification tree: richer (unadjusted overweight percentage $=58.2 \%$ ), poorest (unadjusted overweight percentage $=8.7 \%$ ) and middle (unadjusted overweight percentage $=22.9 \%$ ). We could see differences in three sub-trees. We could not find any predicting variable under the poorest split. However, for both the richer and middle, age proved to be the best predicting variable. For the richer age $<25$ years, higher and secondary education found to be most important predicting variable of being overweight and obese. Under this split, type of place of residence (both urban and rural) also found to be important predicting variable of being overweight and obese. Also, for the age 25-34 and $\geq 35$ years, educational level (higher, secondary, no education, primary) found to be most important predicting variable. Among these three sub splits, only place of residence (rural, urban) found to be important predicting variable under secondary education level. We did not find any important predicting variable in others two splits. Finally, we also did not find any predicting variable under the wealth index named "middle" splits.

\section{DISCUSSION}

In this, the first nationally representative study in Bangladesh that used the decision tree approach to find out the most important risk factors of being overweight. We select nine variable that may be the possible determinant of overweight and obesity. However, only four variable i.e wealth index, age, educational level and place of residence found to be most important determinant factor of being overweight and obese by decision tree approach.

We found wealth index as the most important predictors of being overweight and obese. The demographic and health survey developed wealth index to measure the inequalities; in household characteristics, in the use of the health and others services, and health outcomes [22]. It was constructed using household asset data via principal components analysis [23] and serves as an important indicator of the household level wealth that is consistent with expenditure and income measure [24]. Change in diet and activity pattern are fueling the obesity epidemic in the developing countries like Bangladesh [3]. In the recent decades most countries in the Asia and have experienced a shift in the overall structure of its dietary pattern [25]. People now more interested to increase consumption of fat, added sugar in the diet and Western diet [25]. These factors may lead to the increase prevalence of overweight and obesity in Bangladesh, especially among the higher socio-economic status groups. Many others study conducted in Bangladesh found the similar result $[6,26,27]$. However, in developed countries higher prevalence of overweight and obesity reported among poor socio-economic groups [28]. This negative association may be attributable to lower energy expenditure and the ability to afford food and energy-dense food [28].

Highest educational level found to be another important determinant of being overweight and obese. A recent comparative study in Bangladesh also noticed the higher prevalence of overweight and obesity among the higher educated women [6]. Cohen et al [29] recently conducted a systematic review includes 289 articles that report on 410 populations in 91 countries. They found inverse association between educational level and obesity in higher-income countries and positive association in lower income countries. Different studies reported higher education associated with socio-economic positions, occupation and income [30-32]. Higher educated people are more likely to be involved higher job position that yielding better income. Also they are mainly live in urban area with sufficient transportation facilities which decrease the chance of physical activity. These factors contribute to the increase prevalence of overweight and obese population among the higher educated group especially in urban area. This study also reported urban women were more likely to be overweight. The direction of our result supported by the literature described above. However, previous study conducted in Bangladesh and others Asian countries also found similar result $[2,6,26]$.

This study identified women age as a important determinant of being overweight and obese. Higher prevalence of overweight and obesity reported among the women aged more than 25 years. Study conducted in Bangladesh and India found the similar direction of result [2,6]. Completion of education and changing life style may work as a common risk factors of increasing prevalence of obesity in this age. 
In Bangladesh, majority of the women completed their education during this age range and involved different form of jobs; which may introduce women with modern settings of life. Lower age at marriage also found to be associated with increasing prevalence of overweight and obesity which is common in Bangladesh [33].

The primary strength of this study is to use the decision tree approach to identify the determinants factors of being overweight and obesity. Previous studies in Bangladesh identify the determinants of overweight and obesity by conventional logistic regression analysis. The result of the conventional logistic regression model limited to additive effects of each variable which may overlook the risk factors [34]. In this perspective, decision tree approach yielding a better result. However, in this study, we are not able to justify our findings without comparison of conventional logistic regression analysis due to the lack of appropriate literature.

\section{CONCLUSIONS}

This study found four key determinants of being overweight and obese by Decision tree approach. The selected determinants were wealth index, age, highest educational level and place of residence. Policies to address these determinants are needed to reduce the prevalence of overweight and obesity.

\section{Acknowledgement:}

The author gratefully acknowledged the Department of Population Science, Jatiya Kabi Kazi Nazrul Islam University, Mymensingh, Bangladesh where this study was conducted. The author is also thankful to the authority of Bangladesh Demographic and Health Survey for their cooperation in providing the data.

\section{List of abbreviations}

BMI: Body mass Index, CHAID: Chi-squared Automatic Interaction Detection, BDHS: Bangladesh Demographic and Health Survey.

\section{Declaration}

Ethics: This paper is based on analysis of secondary data.

Consent to publish: BDHS had taken written consent from each of the individual.

Competing interests: The author declares that there is no conflict of interest.

Availability of data and materials: Data and materials are available in Demographic and Health Survey website (http:/ / www.dhsprogram.com).

\section{References}

1. Kordas K, Centeno ZYF, Pachón H, Soto AZJ: Being overweight or obese is associated with lower prevalence of anemia among Colombian women of reproductive age. The Journal of nutrition 2013, 143(2):175-181.

2. Subramanian S, Perkins JM, Khan KT: Do burdens of underweight and overweight coexist among lower socioeconomic groups in India?The American journal of clinical nutrition 2009, 90(2):369-376.

3. Monteiro CA, Moura EC, Conde WL, Popkin BM: Socioeconomic status and obesity in adult populations of developing countries: a review. Bulletin of the World Health Organization 2004, 82(12):940-946.

4. Lee J, Houser RF, Must A, de Fulladolsa PP, Bermudez OI: Socioeconomic disparities and the familial coexistence of child stunting and maternal overweight in Guatemala. Economics \& Human Biology 2012, 10(3):232-241.

5. Popkin BM: The nutrition transition in the developing world. Development Policy Review 2003, 21(5-6):581-597.

6. Khan MN MM, Islam MR, MA A-M, M S: Trends in Body Mass Index and its Determinants among Ever-married Non-pregnant Women in Bangladesh. Mal J Nutr 2015, 21(2):191-205.

7. Khan M, Krämer A: Factors associated with being underweight, overweight and obese among ever-married non-pregnant urban women in Bangladesh. Singapore medical journal 2009, 50(8):804.

8. Corsi DJ, Finlay JE, Subramanian S: Weight of communities: A multilevel analysis of body mass index in 32,814 neighborhoods in 57 low-to middle-income countries (LMICs). Social Science \& Medicine 2012, 75(2):311-322.

9. Hou X, Jia W, Bao Y, Lu H, Jiang S, Zuo Y, Gu H, Xiang K: Risk factors for overweight and obesity, and changes in body mass index of Chinese adults in Shanghai. BMC Public Health 2008, 8(1):389.

10. Fleischer NL, Roux AVD, Alazraqui M, Spinelli H: Social patterning of chronic disease risk factors in a Latin American city. Journal of Urban Health 2008, 85(6):923-937.

11. Parra DC, Lobelo F, Gómez LF, Rutt C, Schmid T, Brownson RC, Pratt M: Household motor vehicle use and weight status among Colombian adults: are we driving our way towards obesity?Preventive medicine 2009, 49(2):179-183.

12. Wen LM, Rissel C: Inverse associations between cycling to work, public transport, and overweight and obesity: findings from a population based study in Australia. Preventive medicine 2008, 46(1):29-32. 
13. Bowman SA: PEER REVIEWED: Television-Viewing Characteristics of Adults: Correlations to Eating Practices and Overweight and Health Status. Preventing chronic disease 2006, 3(2).

14. Hu FB, Li TY, Colditz GA, Willett WC, Manson JE: Television watching and other sedentary behaviors in relation to risk of obesity and type 2 diabetes mellitus in women. Jama 2003, 289(14):1785-1791.

15. Fernald LC: Socio-economic status and body mass index in low-income Mexican adults. Social science \& medicine 2007, 64(10):2030-2042.

16. Jacoby E, Goldstein J, López A, Núñez E, López T: Social class, family, and life-style factors associated with overweight and obesity among adults in Peruvian cities. Preventive medicine 2003, 37(5):396-405.

17. Bernabe-Ortiz A, Gilman RH, Smeeth L, Miranda JJ: Migration Surrogates and Their Association With Obesity Among Within-Country Migrants. Obesity 2010, 18(11):2199-2203.

18. Marshall RJ: The use of classification and regression trees in clinical epidemiology. Journal of clinical epidemiology 2001, 54(6):603-609.

19. Viikki K, Juhola M, Pyykkö I, Honkavaara P: Evaluating training data suitability for decision tree induction. Journal of medical systems 2001, 25(2):133-144.

20. Gandomi AH, Fridline MM, Roke DA: Decision tree approach for soil liquefaction assessment. The Scientific World Journal 2013, 2013.

21. Chevalier P, Cadi F, Scridon A, Girerd N, Bejan-Angoulvan T, Morel E, Hot IJ, Di Filippe S, Ganne C, Colin C: Prophylactic Radiofrequency Ablation in Asymptomatic Wolff-Parkinson-White Patients Is Not Yet a Good Strategy: A Decision Analysis. Circulation: Arrhythmia and Electrophysiology 2013:CIRCEP. 112.970459.

22. Rutstein S, Johnson K, Gwatkin D: Poverty, health inequality, and its health and demographic effects. In: Annual Meeting of the Population Association of America, Los Angeles, California: 2000; 2000.

23. Research NIoP, Training, Mitra, Associates, Demographic MIIfRD, Surveys H: Bangladesh Demographic and Health Survey: National Institute of Population Research and Training (NIPORT); 2011.

24. Rutstein S: Wealth versus expenditure: Comparison between the DHS wealth index and household expenditures in four departments of Guatemala. Calverton, Maryland: ORC Macro 1999.

25. Popkin BM: The nutrition transition and obesity in the developing world. The Journal of nutrition 2001, 131(3):871S-873S.

26. Abbas M, Paracha PI, Khan S, Iqbal Z, Iqbal M: socio-demographic and dietary determinants of overweight and obesity in male pakistani adults. European Scientific Journal 2013, 9(33).

27. Acharya B, Chauhan HS, Thapa SB, Kaphle HP, Malla D: Prevalence and socio-demographic factors associated with overweight and obesity among adolescents in Kaski district, Nepal. Indian Journal of Community Health 2014, 26(6):118-122.

28. Zienczuk N, Egeland GM: Association between socioeconomic status and overweight and obesity among Inuit adults: International Polar Year Inuit Health Survey, 2007-2008. International journal of circumpolar health 2012, 71.

29. Cohen AK, Rai M, Rehkopf DH, Abrams B: Educational attainment and obesity: a systematic review. Obesity Reviews 2013, 14(12):989-1005.

30. Krieger N, Williams DR, Moss NE: Measuring social class in US public health research: concepts, methodologies, and guidelines. Annual review of public health 1997, 18(1):341-378.

31. Chandola T, Clarke P, Morris J, Blane D: Pathways between education and health: a causal modelling approach. Journal of the Royal Statistical Society: Series A (Statistics in Society) 2006, 169(2):337-359.

32. Schnittker J: Education and the changing shape of the income gradient in health. Journal of Health and Social Behavior 2004, 45(3):286-305.

33. Al Nsour M, Al Kayyali G, Naffa S: Overweight and obesity among Jordanian women and their social determinants. EMHJ 2013, 19(12).

34. Batterham PJ, Christensen H, Mackinnon AJ: Modifiable risk factors predicting major depressive disorder at four year follow-up: a decision tree approach. BMC psychiatry 2009, 9(1):75. 